EESTI NSV TEADUSTE AKADEEMIA TOIMETISED 1955. IV kd., nr. 2 ИЗВЕСТИЯ АКАДЕМИИ НАУК ЭСТОНСКОИ ССР 1955. Том IV, № 2

\title{
1905. a. 16. OKTOOBRI VERETÖÖ OHVRITE NIMEKIRI
}

\section{H. SAHA}

Töörahva kangelaslik võitlus esimese vene kodanlik-demokraatliku revolutsiooni päevil on teema, mis on õigusega paelunud ja paelub nõukogude ajaloolasi. Eriti viimasel ajal on ka rida eesti nõukogude ajaloolasi kirjutanud sisukaid töid 1905.-1907. a revolutsioonilistest sündmustest Eestis (H. Moosberg, M. Lõhmus .jt.). Kahjuks esineb meie ajaloolaste kõige viimasteski käsitlustes 1905.-1907. a. revolutsiooni kohta Eestis eksitav faktiline viga. 16. (29.) oktoobril Tallinnas Uuel turul toi-, munud veretöö tagajärjel surmasaanute arvu hinnatakse kuuekümnele, mis aga, nagu selgub, on tegelikust arvust tunduvalt väiksem ${ }^{1}$.

Omal ajal asus 1905. aasta 16 . oktoobri veretöö ohvrite tegeliku arvu selgitamisele saksa fašistide poolt mõrvatud noor ajaloolane A. Looring. Osa tema poolt kogutud materjali, mis kahjuks siiski on lünklik, on säilinud Eesti NSV Teaduste Akadeemia Ajaloomuuseumi Arhiivis.

Esimesena avaldas tõepärased andmed 1905. aasta 16. oktoobri veretöö ohvrite kohta $M$. Aitsam juba 1940 . aastal ${ }^{2}$. Tema poolt koostatud nimekirja järgi sai surma või suri haavadesse 86 inimest. Kahjuks on aga M. Aitsam jätnud oma nimekirjas märkimata veretöö ohvrite töökohad. Nimekirjas esineb ka väiksemaid faktilisi vigu, eriti nimevormides.

16. oktoobri veretöö ohvrite väljaselgitamisel kasutasime järgmisi allikaid. Kõigepealt võeti vaatluse alla 16 . oktoobri veretöö ohvrite ühisel matusepaigal Rahumäe kalmistul säilinud hauamonumendid. Seal asuvast 59 hauast on 53 16. oktoobri veretöö ohvrite omad, 1 14. oktoobril 1905. aastaI tsaarivõimude poolt tapetud töölise haud, 1 1917. aastal surnud vana revolutsionääri haud, 2 1920. aastal tapetud revolutsionääride hauad, 2 revolutsionääride sugulaste hauad (aastatest 1920 ja 1949). 53-st 16. oktoobri veretöö ohvrite hauast on 33 varustatud nimede ja pealkirjadega kaetud hauamonumentidega ${ }^{3}$. Ülejäänud kahekümnel haual need puuduvad ja neist õnnestus identifitseerida ainult kaks (Kruugi ja Piibori hauad).

Hindamatut abi osutasid autorile Eesti NSV Miilitsavalitsuse Vabariikliku Perekonnaseisuaktide Arhiivi töötajad, kes säilinud meetrikaraamatute põhjal selgitasid 31 Uuel turul toimunud veretöö ohvri nimed.

lk. 230 .

1 Vt. näit. Eesti NSV ajalugu (kōige vanemast ajast tänapäevani), Tallinn, 1952,

2 "Rahva Hääl”, 29. okt. 1940, a.

3 Mõned hauamonumentidel olevaist pealkirjadest on ōige ilmekad - näiteks „Sinu veri olgu õliks vabaduse tulesse." 
Tallinna Linna ja Harju rajooni Riiklikust Arhiivist õnnestus leida materjale 16. oktoobri veretöö tagajärjel kannatada saanud perekondadele toetuse andmise kohta Börsikomitee poolt ${ }^{4}$. Börsikomitee poolt anti 122 inimesele kogusummas 9250 rubla eest toetust, kuna 10 inimesele 609 rubla ulatuses määratud toetus jäeti millegipärast välja maksmata. Kogu Börsikomitee asjaajamine näitab, et toetuse jagamisega püüti olla võimalikult kokkuhoidlik. Et puuduses virelevad töölised ei saaks ühtki „liigset” kopikat, jagati toetuse taotlejad toetuse suuruse määramisel. järgmistesse kategooriatesse: 1) kergesti haavatud, ilma puudustkannatavate perekonnaliikmeteta; 2) raskesti haavatud, ilma puudustkannatavate perekonnaliikmeteta; 3$)$ kergesti haavatud, puudustkannatavate perekonnaliikmetega; 4) raskesti haavatud, puudustkannatavate perekonnaliikmetega; 5) perekonna toitja (abiülalpidaja) surma saanud; 6) ülalpidaja surnud, naine järele jäänud kahe kuni 12 a. vanuse lapsega; 7) ülalpidaja surnud, naine järele jäänud rohkem kui kahe lapsega; 8) surmasaanu jättis järele kuni kaks vaeslast; 9) surmasaanu jättis järele rohkem kui kaks vaeslast; 10) surmasaanu jättis järele ülalpeetava vigase; 11) toitja (abiülalpidaja) vigane; 12) ülalpidaja vigane.

Börsikomitee materjalid sisaldavad väärtuslikke andmeid tapetute ja haavatasaanud töökoha, elukoha, perekonnaseisu, vanuse jm. kohta.

Kõik kasutatud allikad näitasid veenvalt, et tegelikult sai 1905. aasta 16. oktoobril Tallinnas Uuel turul korraldatud veresauna tagajärjel surma 90-100 inimest, ning et Uuel turul surma ja havata saanud inimestest töötas enamik Tallinna suuremates käitistes.

\section{AASTA 16. OKTOOBRIL TALLINNAS UUEL TURUL TSAARIVÖIMUDE POOLT KORRALDATUD VERESAUNA OHVRITE NIMEKIRI (TOOOKOHTADE JARGI)}

\section{„Dvigatel”}

Tapetud ja haavadesse surnud:
1. Anton Dikker
2. Elias Eduard Duberg
3. Karl August Edasi
4. Peeter Holm
5. Hans Kesberg
6. Peeter Kesselman
7. Aleksander Krais
8. Jaan Kroll
9. Jüri Mildoff

$\mathrm{H}$ a a v a tud:

1. Villem Feodorov

2. Eduard Karjahärm (jäi invaliidiks)

3. Aleksander Kasfeld

4. Karla Klemmer

5. Marie Kroll

6. Juhan Liivak

7. Aleksander Maikov

8. Eeva Mildohv

9. Tõnu Orav

10. Anton Pullas-Pullers

11. Johannes Reital-Rettal (jăi invaliidiks)
10. Kaarel Ornefeld
11. Andres Peegel
12. Jaan Peekman
13. Aleksander Pritso
14. Aleksander Schmidt
15. Gustav Stolzen
16. Jaan Terik
17. Jüri Triik
18. Priidik Trommel

4 Tallinna linna ja Harju rajooni Riiklik-Arhiiv, f. 116, nim. 1, sü 1727.

5 Tööliste perekonnaliikmed on ära toodud tööliste töökohtade järgi. Köigi haavatute nimesid kindlaks teha ei ōnnestunud; havatute koguarv oli umbes 300 . 
T a petud $\mathrm{j}$ a havadesse surnud:
1. Mihkel Kadakas
2. Eduard Pessa
3. Jakob Preitoff
4. Aleksander Pällo

1. Bernhard Kuhlberg

2. Liisa Pessa

\section{Alfred Romberg \\ 6. Mihkel Tammik \\ 7. Jaan Treiman}

$\mathrm{H}$ a a v a t u d:

3. Johan Tiits

4. Johan Rumjantsev

\section{„Tallinna Metallivabrik" (.Lausmann”)}

S urnud:

1. Tõnu Keeba

$\mathrm{H}$ a a v a tud:

1. Alfred Perger

\section{„Krull”}

.Tapetud ja haavadesse surnud:

1. Johannes Kamp

2. Rudolf Karro

1. Jaan Mennov

2. Johannes Liuska
3. August Künamägi .

$\mathrm{H}$ a a v a tud:

3. Gerhard Scherwell (jäi invalididiks)

\section{"Luther"}

Tapetud ja haavadesse surnud:

1. Karl Härjamäe (Gerjame)

2. Aleksander Jerlet
3. Jakob Reisman

4. Priido Viita

$\mathrm{H}$ a a v a $\mathrm{u}$ :
1. Karl Inslerman
2. Jaan Kukk (jäi invafiidiks)
3. Leopold Livental
4. Juulie Reisman (jäi invaliidiks)
5. Eduard Tikkerman
6. Juhan Vapris

\section{„Balti Puuvillavabrik”}

Tapetud ja havadesse surnud:

1. Leena Busch

2. Karl Mill
1. Maria Aul
(jäi invaliidiks)
2. Anna Kirilovits
(jäi invaliidiks)

$\mathrm{H}$ a a v a t u d:
3. Maria Lao (jäi invaliidiks)
4. Emilie Limberg
5. Jaan Niilman (jäi invaliidiks)

\section{„Raudteetehased"}

Tapetud ja ha avadesse surnud:
1. Johannes Armberg
2. Alfret Bauert
3. Tiit Kask

\section{August Reisman}
4. August Korton
5. Julius Palmkron

$\mathrm{H}$ a a v a t ud: 
$\mathrm{H}$ a a $v$ a $\mathrm{tud}$ :

1. Voldemar Schmidt

1. Leonhard Bergman

2. Johannes Essenberg

3. Leonid Ostanin

(jăi invaliidiks)
2. Hans Tammik

Plekitööstus „Zvezda”

$\mathrm{H}$ a a v a $\mathrm{ud}$ :

4. Adrian Treier

\section{Mitmesugused muud tööstused ja tööharud}

Tapetud ja havadesse surnud:

1. Sahhari Holkin, kivitööline

2. Johannes Jōger, kivitööline

3. Anton Kaarman, vabrikutööline

4. Madlena Kruuk, ōmbleja

5. Aleksander Nülg, treial

6. Jaak Orav, maaler

1. Indrik Allikuga, sepp (jäi invaliidiks)

2. Jüri Hio, vabrikutööline

3. Jaan Kuuspuu, voorimees

4. Rudolf Linnaks, sadulsepp (jäi invaliidiks)

5. Gustav Lutsius, pagar

6. Peeter Mürk, vabrikutööline (jäi invaliidiks)
7. Viilip Piibor, maaler

8. Aleksander Saast-Sass, sadulsepp

9. Ferdinand Vatsel, vabrikutööline

10. Otto Vurma, tisler

11. Tõnu Vurma, tisler

$\mathrm{H}$ a a v a tud:

Töökoht, tööala lähemalt määramata

1. Juhan Ambak

2. August Arno

3. Salomon Berkowitz

4. Goldman (tütarlaps)

'5. Jüri Hansman

6. Juhan Hansmitt

7. Mai Hansmitt

8. Johannes Isop

9. Johannes Jalakas

10. Henn Kanter

11. Hans Kivipuur

12. Jüri Koit

13. Karl Kullamaa

14. Aleksander Kuusk

15. Miina Lemloh

16. Mart Limberg

17. Jaan Maid

18. Rudolf Matsar
7. Otto Paimets, sadamatööline

8. Artur Pitk, vabrikutööline (jäi invaliidiks)

9. Richard Treivald, sepp

10. Friedrich Tõnnisson, sadulsepp

11. Anton Uster, kaevuehitaja

12. Jakob Volter, viiliraiuja

\section{Tapetud ja havadesse sur.nu d:}

19. Johan Mitt

20. Juhan Mõtlik

21. Jaan Määra

22. Evald Neiman

23. Jaak Nikker

24. Hindrek Nuia

25. Juhan Nōmm

26. Eliisabet Okas

27. Eduard Pallik

28. Johan Peterson

29. Rudolf Ross

30. Jeremei Sokol

31. Jaan Udelt

32. Jakob Unterberg

33. Miina Vahtrik

34. Robert Wildt

35. Kustav Saar

36.-39.Neli tundmatut

$\mathrm{H}$ a a v a tu d:

1. Anna Adrikonn

2. Jüri Allan

3. Tõnu Enok

4. Eduard Flink

5. Hans Hansen

6. Sofia Ignatjev
7. Julius Jebor

8. Otto Jürgens

9. Priidu Kaar

10. Karl Kraanvelt

11. Voldemar Kranich

12. Robert Laks 
13. Jaan Lell

14. Marta Lepp

15. Maria Lettberg

16. Helene Luuse

17. Richard Muskat

18. Friedrich Nonats (jäi invaliidiks)

19. Herman Org

$$
\text { (jăi invaliidiks) }
$$

20. Jaan Org

21. Karl Pahlberg

22. Hans Pakk

23. Jakob Pastak

24. Voldemar Orras

(jäi invaliidiks)

25. Prants Poland

(jäi invaliidiks)
26. Diina Pestschanski (Petschalski)

27. Ado Rosenstrauch

28. Tõnis Pöör

29. Voldemar Saalberg

30. Albert Vahter (jäi invaliidiks)

31. Leena Schwarzbach (jäi invaliidiks)

32. Juhan Siirak

33. Eduard Soobah

34. Jaan Schönberg

35. Seiler

36. Gustav Sulg

37. Liisa Tornea

38. Eduard Tuukman

39. Rosalie Siispool

40. Liisa Välja

41. Leena Ounpuu

Kokkuvōōte

\begin{tabular}{|c|c|c|}
\hline Töökoht (või tööala) & $\begin{array}{l}\text { Surnud (ta- } \\
\text { petud või } \\
\text { haavadesse } \\
\text { surnud) }\end{array}$ & $\begin{array}{l}\text { Nimeliselt } \\
\text { kindlaksteh- } \\
\text { tud haava- } \\
\text { tud võil } \\
\text { vigastatud }\end{array}$ \\
\hline $\begin{array}{l}\text { „Dvigatel" } \\
\text { "Volta" } \\
\text { "Tallinna Metallivabrik" (Lausmann) } \\
\text { „Krull" } \\
\text { „Luther" } \\
\text { Balti Puuvillavabrik (Sitsivabrik) } \\
\text { "Raudteetehased" } \\
\text { "Zvezda" (plekitööstus) } \\
\text { "Wiegand" } \\
\text { Mitmesugused ettevõtted } \\
\text { Tööala lähemalt määramata (andmed } \\
\text { puuduvad) }\end{array}$ & $\begin{array}{r}18 \\
7 \\
1 \\
3 \\
4 \\
2 \\
5 \\
- \\
11 \\
39\end{array}$ & $\begin{array}{r}22 \\
4 \\
1 \\
3 \\
6 \\
5 \\
2 \\
4 \\
2 \\
12\end{array}$ \\
\hline & 90 & 102 \\
\hline
\end{tabular}

Saabus toimetusse

9. IX 1955

\title{
ПОИМЕННЫЙ СПИСОК ЖЕРТВ КРОВАВОГО ЗЛОДЕЯНИЯ ЦАРИЗМА 16 ОКТЯБРЯ 1905 Г.
}

\author{
X. A. CAXA
}

\section{Резюме}

До сих пор в исторической литературе количество убитых на Новом рынке в Таллине 16 октября 1905 г. в результате расстрела митинга трудящихся царскими войсками определялось в 60 человек. Продолжая работу А. Лооринга и $M$. Айтсама, удалось установить на основе изучения различных источников, что количество убитых и умерших от ран составляет не менее 90 человек. 